\author{
Case Study
}

\title{
Supporting the role of universities in leading individual and societal transformation through education for sustainable development
}

\author{
Elizabeth A. C. Price ${ }^{1}(\mathbb{D}) \cdot$ Rehema M. White $^{2}$ (I) $\cdot$ Kate Mori $^{3}$ (D) James Longhurst ${ }^{4}$ (D) $\cdot$ Patrick Baughan $^{5}$ (D)

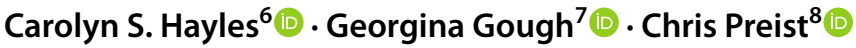

Received: 26 August 2021 / Accepted: 1 November 2021

Published online: 11 November 2021

(c) The Author(s) 2021 OPEN

\begin{abstract}
There is growing recognition of the value of Education for Sustainable Development (ESD) for all learners, and of the unique role that universities play in the transformation of individuals, institutions and societies towards more sustainable futures. Universities engage and even lead in several areas: education, research and community engagement, all of which are essential in this transformation. Further, given their focus and influence, universities are pivotal to action needed to realise the UN Sustainable Development Goals (SDGs) but, to date, UK university integration of ESD and engagement with the SDGs is relatively limited. In recognition that a more urgent and meaningful response is needed to deliver the 2030 targeted socio-economic transformation outlined by the SDGs, the UK ESD Guidance has been comprehensively revised to support universities to deliver education which enables students to acquire sustainability competencies, equipping them to play leadership roles in an increasingly uncertain world. In this case study, we critically analyse the role of universities and explore why ESD needs to be more urgently integrated in teaching and learning. We review the barriers to achieving ESD in UK universities at political and institutional levels. Finally, we explore the policy-practice interface and outline how the new UK ESD Guidance can support universities in leading individual and societal transformation through ESD and act as a stimulus for embedding ESD in university curricula in both UK and international contexts. We conclude that universities have as yet unfulfilled potential to explore and facilitate ESD for sustainability leadership.
\end{abstract}

\section{Introduction}

We are facing global environmental challenges that threaten to overstep our planetary boundaries, whilst social inequalities have been exacerbated [1,2]. Sustainable development is offered as a route to envision better futures and address these challenges. It is no longer a marginal concept and has now been mainstreamed in policy, business and many practice contexts across society as a whole. The UN Sustainable Development Goals (SDGs) were launched in 2015 to create a global framework and impetus for action in transforming our world for a more sustainable future [3]. The SDGs recognise

$\triangle$ Elizabeth A. C. Price, e.price@mmu.ac.uk; Rehema M. White, rehema.white@st-andrews.ac.uk; Kate Mori, k.mori@qaa.ac.uk; James Longhurst, James.Longhurst@uwe.ac.uk; Patrick Baughan, patrick.baughan@advance-he.ac.uk; Carolyn S. Hayles, cshayles@ cardiffmet.ac.uk; Georgina Gough, Georgina.Gough@uwe.ac.uk; Chris Preist, Chris.Preist@bristol.ac.uk|'Department of Natural Sciences, Manchester Metropolitan University, Manchester, UK. ${ }^{2}$ School of Geography and Sustainable Development, University of St Andrews, St Andrews, Scotland and Learning for Sustainability Scotland, St Andrews, Scotland. ${ }^{3}$ Quality Assurance Agency for Higher Education, Gloucester, UK. ${ }^{4}$ Faculty of Environment and Technology, University of the West of England, Bristol, UK. ${ }^{5}$ Advance HE, York Science Park, York YO10 5BR, UK. ${ }^{6}$ Cardiff School of Art and Design, Cardiff Metropolitan University, Cardiff, UK. ${ }^{7}$ Department of Geography and Environmental Management, University of the West of England, Bristol, UK. ${ }^{8}$ Department of Computer Science, University of Bristol, Bristol, UK. 
the climate and nature emergencies, pollution, poverty and inequalities and the interlinkages between these challenges $[4,5]$, However, whilst the aspirations of the ambitious UN Agenda 2030 for transformation are laudable, there remain multiple interpretations of 'sustainable development' and significant challenges in the implementation of this agenda [6].

Universities have a critical role in both pursuing and critically interrogating the SDGs and their consequences. The SDGs combine an aspirational vision for transforming our world, whilst setting out an agenda for 2030 [3]. The 17 SDGs and 169 targets demonstrate the priorities of a broad range of civil society voices [7]. The intention is for a different form of development, that is rights based and focused on addressing inequalities $[8,9]$ However, the SDGs have been critiqued, for example, for their western ontology [10] and for their promotion of neoliberal development models which can disenfranchise indigenous communities [11]. It is also not clear how their interactivity will be navigated in practice [6]. That said, the SDGs when considered as an indivisible whole, are useful for Education for Sustainable Development (ESD) in representing the wide framing and scope of sustainable development, illustrating a holistic view of interconnected environmental, economic, cultural and social issues and dimensions and encouraging interdisciplinarity [12, 13]. By including the SDGs in teaching and learning, universities are enabling future graduates to contribute to this global sustainability agenda. Encouraging students to critically, yet constructively, assess the SDGs can help empower graduates to effectively design the next steps towards sustainability, post 2030.

ESD has been defined in various ways, but a recent framing by UNESCO [14] captures many aspects.

'ESD empowers learners to take informed decisions and responsible actions for environmental integrity, economic viability and a just society, for present and future generations, while respecting cultural diversity. It is about lifelong learning, and is an integral part of quality education. ESD is holistic and transformational education which addresses learning content and outcomes, pedagogy and the learning environment. It achieves its purpose by transforming society.'

ESD can contribute towards a sustainable future and is fundamental to achieving humanity's transformative challenge, as UNEP [15] highlights, 'Providing a decent life and well-being for nearly 10 billion people by 2050, without further compromising the ecological limits of our planet and its benefits, is one of the most serious challenges and responsibilities humanity has ever faced'.

The 'Decade of Action to Deliver the SDGs' by taking action to 'end poverty, protect the planet and ensure that all people enjoy peace and prosperity by 2030' began in 2020 [16], yet on current trajectories, we are unlikely to meet this transformative challenge [17]. As educators, we have a responsibility to increase the pace of this action by delivering an education that will prepare people for the environmental challenges they will face in their lifetimes, equip them to be resilient, adaptable, skilled and knowledgeable, ensure that students develop the capabilities and confidence to effectively challenge unsustainable policies, practices and behaviours and enact more sustainable alternatives as they confront a range of global environmental challenges related to a rapidly changing climate [18].

There have been multiple calls to strengthen ESD in higher education. Some policy initiatives have attempted to strengthen uptake [19]. For example, in the United Kingdom (UK), the Quality Assurance Agency (QAA) and Higher Education Academy (HEA) produced guidance in 2014 to encourage uptake of ESD within universities [20]. This 2014 guidance is not mandatory and although it has been a useful instrument to accelerate curricular ESD integration, uptake and implementation of the guidance in the UK has not been ubiquitous [21]. Other examples of initiatives relevant to ESD include the Green League (UK), [22], the Sustainability Tracking, Assessment and Ratings System (STARS, in the United States [23]), and the Times Higher Education (THE) international 'impact rankings', based partly on the aforementioned SDGs [24]. Embedding ESD in higher education aligns with and supports other contemporary agendas such as entrepreneurship, inclusivity, decolonisation of the curriculum and civic engagement, all of which require critical thinking, reflexivity and the ability to address real world problems. The drive for inclusivity and access in the student cohort enhances ESD learning by increasing the diversity of perspectives in active discussion, and ESD explicitly explores social justice and inequalities. Despite enhanced recognition of the importance of ESD in universities and increased engagement in the UK, ESD remains a largely niche activity in Higher Education Institutions [21, 25]. In recognition that a more urgent and meaningful response is needed to deliver the 2030 targeted socio-economic transformation outlined by the SDGs, the UK ESD Guidance, (hereafter referred to as 'the Guidance'), has recently been comprehensively revised by QAA/ Advance $\mathrm{HE}$ and was published in March 2021. A key aim of the Guidance is to support universities to deliver education which enables students to acquire sustainability competencies [26, 27], equipping them to play leadership roles in an increasingly uncertain world [28]. The Guidance also emphasises the need for a whole institution approach to progressing sustainable development and the important role of senior leadership teams, as well as student representatives, in enabling this to happen. 
The new Guidance plays a supporting role in encouraging and enabling individuals and universities to strengthen and embed ESD. However, for the Guidance to have impact, leadership within the university at all levels is essential. Leadership at a senior level can promote a whole-institution approach, and develop a positive culture that recognises and addresses sustainable development imperatives across all areas of activity. Course and programme leaders can lead in the incorporation of ESD pedagogies and curricula. Individual academic staff can inspire and inform through their teaching. Students can demand and take forward a sustainability focus. Beyond this, sector-wide higher education organisations can provide advice and support for the academic community to collectively strive to engage societies for the future. In this way, leadership at different levels within the university sector facilitates the graduation of students who can in turn play a leadership role in the pursuit of sustainable development in the future.

The aim of this paper is to examine the role of leadership on ESD within universities in supporting the individual and societal transformation necessary to create a better future. We do so through an adapted Delphi exercise used in the QAA/ Advance HE process to revise the Guidance, and explore potential application of the Guidance, throughout the UK and in international contexts $[29,30]$. In this case study, we review the role of universities and explore why ESD needs to be more urgently understood and integrated in teaching and learning. We identify the barriers to achieving ESD in UK universities at a political and institutional level. Finally, we explore the policy-practice interface and critically analyse how the Guidance will function to support universities to play a leading role in individual and societal transformation.

\section{Methods}

This paper uses a process of consultation and critical reflection through an adapted Delphi exercise [29, 30], drawing on experiential learning by the authors in the field of ESD in higher education. The Delphi method involves structured group communications to achieve a reliable consensus of opinion and requires that a panel of experts on the subject under study be selected [29]. All authors were members of the expert advisory group, convened by two Chairs in 2020 on behalf of QAA/ Advance HE to update the UK ESD Guidance. Seventeen members of the advisory group were invited by the two Chairs from across the UK, based on their experience of ESD within the higher education sector, or in student representation, or their work with employers and enterprise to facilitate sustainable development practice. This paper represents a reflexive analysis [31] of the imperative and routes for ESD. The expert advisory group met in February 2020 when stimulus questions were posed to members seeking their opinions based on their experienced judgement. The responses were then translated into statements about which consensus was sought by refinement through discussion and feedback. Anonymous participation is typically a requirement of the Delphi process, but in a variation of the technique to facilitate discussion [29], the advisory group had ongoing regular online meetings at approximately bi-monthly intervals until January 2021 to discuss and develop the Guidance, in addition to anonymous written contributions via a public consultation process. Lead individuals were allocated to sections, with contributing teams. Vigorous discussion and multiple drafts led to the release of a consultation Guidance document in December 2020. The consultation document was widely advertised via QAA and Advance HE networks and contributions sought from anyone with an interest in higher education in the UK, including representatives from all four countries of the UK; prospective, current and past students; staff from the full range of higher education providers, including academic staff and staff with responsibilities for quality assurance; and from employers, who depend upon the abilities, skills and knowledge of graduates. A pre-designed consultation survey helped guide commentary and we also accepted direct feedback via the Chairs and QAA/Advance HE representatives. A total of 92 responses were received via the survey and a further four directly to the Chairs and QAA. The responses were thematically analysed by the QAA and then shared with the Chairs and advisory group members. Several meetings took place to revise the Guidance in light of the key themes arising from the consultation feedback. Revisions were made across all four sections, and the Guidance was subsequently published in March 2021. This paper draws heavily on the principles and practices that were agreed to be important to the embedding of ESD in higher education, and extends this work to highlight leadership opportunities within universities to inspire leadership in graduates. The authors used an iterative form of drafting to collaboratively determine key points, drawing on the new Guidance document, literature and professional and personal experience.

\section{The role of universities in enabling transformation via ESD}

The purpose of universities has been debated for centuries, but they are expected to act as leaders and mentors in society, to deepen understanding of societal challenges and to design technological and policy solutions [32]. Universities have a significant role to play in considering and pursuing more sustainable futures [33]. Universities provide value to the 
economy, society and environment through education, research, innovation, community engagement, leadership and influence, as well as through developing the potential of their students as citizens and societal influencers [25, 34-36]. Higher education can create the attitudes, changes and leadership necessary for the transformation of societies [37] and the influence and reach of universities is considerable, since successful global leaders come from higher education backgrounds in every region of the world [38]. Whilst their research, education and community engagement are important contributions $[39,40]$, higher education is a critical enabler in wider global and local pursuits of sustainability. It should be noted, however, that 'the worth of education must now be measured against the standards of decency and human survival-the issues now looming so large before us in the twenty-first century. It is not education, but education of a certain kind, that will save us' [41]. Discussions surrounding the 'new power university' [42] have emphasised that a different and evolving purpose for universities is necessary, through the application of a new set of values that puts social responsibility at the core of the academic mission, allowing higher education institutions to become advocates for what really matters for their students and broader communities. The shift from a rules based to a principles or outcomes based regulatory environment within England also further promotes the possibility for this vision to be realised.

There is growing recognition that ESD supports learners across all academic disciplines in developing the subject relevant competencies to create and pursue visions of a better world, and that recognise their current and future social, cultural, economic and environmental impacts, from a local and a global perspective [43]. There have been pleas for teaching and learning within universities towards visions of the future in which our scientists, technologists and business managers design activities to sustain rather than degrade our natural environment and to support human health and wellbeing $[41,44]$. ESD is not merely learning about sustainable development, but rather learning for sustainability [45]. It can, in fact, be a route to overall enhanced forms of learning, emphasising transformative rather than transmissive approaches, employing experiential learning and critical pedagogy and using real world examples [46]. It is a process, rather than a product. Social responsibility and sustainability skills, knowledge and attributes can equip students to be resilient, adaptable, skilled and knowledgeable and can give them agency to drive a better future [18]. Many ideas concerning the integration of sustainability in curricula have been developed, their designs and outcomes published in journals and edited collections [47-51]. Given their focus and influence, universities are crucial in contributing to the actions needed to realise the UN SDGs. Universities have a critical responsibility to provide education to address the SDGs to as many learners as possible within their sphere of influence [25]. However, univerisities also play a unique role in constructive critique of the Agenda 2030 and in monitoring how its implementation affects people, places and processes around the world [11].

ESD forms a major aspect of holistic, whole institution approaches to sustainability in universities. The notion of a 'sustainable university' has amplified the imperative for universities to contribute to individual and societal transformation for sustainability [33]. A sustainable university can be understood in many ways, but has been described as:

'one that through its guiding ethos, outlook and aspirations, governance, research, curriculum, community links, campus management, monitoring and modus operandi seeks explicitly to explore, develop, contribute to, embody and manifest - critically and reflexively - the kinds of values, concepts and ideas, challenges and approaches that are emerging from the growing global sustainability discourse.' [33].

Those who work in a sustainable university must thus 'traverse[s] the professional and personal, through demanding reflective practice, critical engagement and transformative teaching' [52].

ESD has become one of the expectations of current and prospective higher education students [21,53]. In a survey of UK students, $88 \%$ of respondents agreed their place of study should actively incorporate and promote sustainable development while $80 \%$ would like to see sustainable development actively incorporated and promoted across all courses [54]. Increasingly, jobseekers want to work for organisations with purpose and which take sustainability and social responsibility seriously 'To attract and retain the next generation of talent, companies need to be willing to let them participate in making a social or an environmental impact regardless of job function or title' [55]. Students have shown an increasing preference for a graduate role with an organisation that has a strong environmental and social record, even if that means a lower starting salary [54].

Whilst the purpose of education is not merely to prepare students for future employment in a capitalist society [56], there are indications that employers are also seeking the competencies conferred through ESD. Beyond the academic community, sustainability capability aligns with priority skills demanded by employers $[57,58]$. To effectively take action towards achieving the SDGs, we need professionals and citizens who have the skills, knowledge, and mindsets to tackle the complex sustainable development challenges articulated by the SDGs through whichever career or life path they take [25] and it has been argued that 'sustainability should not be a bolt-on; it needs to be a core part of everyone's role, 
regardless of their job title' [59]. Collaboration based on entrepreneurship for sustainability can provide sustainable solutions and ideas for development related to the SDGs [60]. Moreover, employers look favourably on the skills, attributes and mindset that enable these behaviours, with intrapreneurship, where innovative employees help to drive change, being particularly highly valued $[60,61]$. Sustainable enterprises are necessary to solve the central problem of finding ways for humanity to survive and flourish, without destroying life-supporting ecosystems [62]. Increasingly, climate transition, inclusive growth and a commitment to sustainable finance are seen as imperative in many sectors [63, 64]. By engaging directly with social entrepreneurs, employers and industry, ESD can align with enterprise and entrepreneurship education to add value to the learner's journey [28].

\section{Barriers to achieving ESD in UK universities}

There are significant challenges for institutions striving to become sustainable universities in contemporary socio-cultural contexts [65]. Whilst universities now have the potential to be 'catalysts for change in an increasingly knowledge-based society', many appear to be responding more to short term market forces [66]. Concern has been expressed for some time over neoliberalism and the subsequent commodification of higher education, with increasing managerial targets threatening to displace a culture and goals for excellent teaching [67-70]. Higher education has to deal with both the negatives and positives of globalisation [71]. A focus on the employability of graduates can neglect wider societal and individual benefits of education and limits its transformative potential [72]. Hence, whilst the integration of sustainability concerns into teaching, research and operation of universities is required, there are difficulties in so doing.

The scale of the change needed to embed ESD across the higher education sector is also both enormous and urgent [25]. Increasing numbers of students, academic staff and stakeholders believe that universities should address issues of sustainability for current and future society $[53,54]$. However, to date, global and UK university integration of ESD is variable. For example, engagement with the SDGs is patchy $[21,73]$. In a worldwide survey of representatives of universities engaged in sustainability networks, only $43 \%$ indicated that their university has made the strategic decision to embed the SDGs in their curriculum [73].

The Guidance review process enacted in this case study reached a consensus that expansion of ESD in universities can be challenging since it requires deep reflection on the suitability of traditional approaches of (1) governance and leadership, (2) learning and teaching, (3) disciplinary structures and (4) measurement of success [25, 36, 53]. Each of these barriers is contextualised below.

\subsection{Governance and Leadership}

ESD prepares learners to adapt to and address the uncertainties of the contemporary world. In this way ESD offers two major challenges to higher education leadership: those of paradigm, demanding a shift in the way we perceive education, and even the role of the university, and of provision, offering processes, resources and support for the embedding of ESD within and across our universities [74]. Both paradigm and provision of ESD require a whole institution agenda. Quality ESD aligns well with research, blurring the managerial imposed duality of teaching / research by emphasising critical thinking, active questioning, interdisciplinarity and interaction with non-academics. ESD lends itself to student projects on local issues and the use of real-world examples in teaching, thereby strengthening community engagement. Whole institution sustainability is no longer optional for universities; those that do not engage with this reality will diminish over time [73].

High-level institutional support for embedding ESD has been identified as critical to the success of ESD in higher education [21, 73]. Strong sustainability leadership can help promote action around a shared vision of ESD [25]. However, sustainability leadership can involve ambiguity and complexity in relation to the scope and level of commitment relevant to a university, how success is measured and how leadership for sustainable development can be delivered [36, 75]. The speed and extent of ESD uptake will also vary. There is a risk that the radical and transformative potential of ESD has been compromised through its collaboration with managerial culture and targets $[33,70]$. Possibly some universities will thus merely tweak the status quo and develop tokenistic responses to address provision, rather than enabling transformative processes and considering paradigmatic change. Such approaches will not deliver meaningful change to society and may be rejected by students demanding authentic commitment. 


\subsection{Learning and teaching approaches}

Activities needed to expand ESD in universities include curriculum change which goes beyond traditional approaches of learning and teaching [25]. ESD is aligned to transformative learning pedagogies (engaging head, hands and heart) and the acquisition of knowledge, capacities and competencies with experiential learning so that students can be empowered as agents of change $[14,25,46,76]$. Incorporating key approaches to ESD, such as action-oriented learning, interdisciplinarity, and multi-actor collaboration, requires commitment but is necessary if transformative learning is to be achieved [25].

\subsection{Discipline context}

Within institutions, diversity in subject specialism and emphasis will further influence the capacity for adopting and embedding ESD. Challenges universities face include engaging staff who may question the relevance of ESD, and who lack understanding regarding its implications for their discipline [25]. Disciplinary benchmarks or professional accreditation may mean the syllabus has little space for what staff do not see to be core content. However, ESD may be incorporated through appropriate case studies, pedagogies and contextualisation of professional content. All disciplines are relevant to ESD and ESD is relevant to all disciplines; not only in terms of practical examples but also the ontological plurality that is conferred. While this is not always understood in different contexts, Koger and Scott [77, 78], for example, demonstrated how psychology makes a major contribution to understanding and changing unsustainable behaviours.

A further challenge relates to interdisciplinary learning and teaching in universities. This approach can bring together contributions from the humanities, social sciences and natural and physical sciences, allowing moral and ethical questions to be addressed in an integrated manner with technological and scientific considerations. However, the academic freedom to design and deliver interdisciplinarity can be limited by factors such as accreditation procedures and disciplinary structures $[25,53]$, and practical issues such as timetabling. The three year undergraduate degree span in universities in England, Wales and Northern Ireland may limit efforts at interdisciplinarity, and the broader base in the four year Scottish degree offers wider scope to explore this.

\subsection{Measuring success}

Universities are increasingly being compared or ranked by engagement with SDGs [25]. However, a further challenge faced by universities in implementing ESD is ambiguity in how sustainability outcomes relate to individual organisational success [36]. There remains a lack of sector-wide agreed metrics for ESD and sustainability in higher education with recognition achieved by a range of awards, accreditations, league tables and frameworks that attribute varied significance to ESD [36]. Furthermore, while sustainability is included in many university graduate attribute statements, the practice of assessing students' sustainability competencies relevant for professional practice is still in its infancy $[58,79]$.

\section{New UK ESD Guidance at the policy-practice interface}

These challenges highlighted the need for sector wide emphasis on and information regarding ESD in the university sector. The QAA Quality Code is used as part of the regulatory environment in the UK to assure the quality and standards of all Higher Education providers. The Quality Code uses a series of key, authoritative reference points to assist in enabling providers to meet the expectations of the Quality Code [80]. These include discipline focussed Subject Benchmark Statements and cross-disciplinary supporting resources, such as ESD Guidance for UK Higher Education Providers (although neither of these are part of the regulatory framework). As outlined above, in recognition that a more urgent and meaningful response is needed to deliver the 2030 targeted socio-economic transformation outlined by the SDGs, and to reflect rapid development within ESD, UK ESD Guidance has recently been comprehensively revised to address some of the challenges linked to embedding ESD in universities.

The Guidance is organised into four sections and as highlighted earlier, was shaped by an extensive consultation process. The first section outlines the interpretation of sustainable development and ESD and offers a rationale for ESD taking prominence across curricula. The second section discusses how to holistically position ESD across curricula and 
highlights UNESCO's key competencies for sustainability and the learning outcomes ascribed to ESD, alongside appropriate teaching and learning approaches. The Guidance highlights that the UNESCO key competencies for sustainability [43] drawn from Wiek et al.[26] (systems thinking, anticipatory, critical thinking, strategic, collaboration, integrated problem-solving, self-awareness and normative competencies) can be adopted and adapted within higher education through alignment with appropriate learning outcomes. The third section introduces a toolkit of reflective questions, competencies, learning outcomes and approaches to teaching, learning and assessment that may prove helpful when designing ESD. This section provides resources to support the design or enhancement of learning outcomes aligned with key competencies for sustainable development. The fourth section offers an annotated reference and resources list for those who may wish to further investigate the academic debate surrounding ESD [28].

We now return to the barriers described in the previous section, and discuss how the Guidance, together with insights from a wider body of research, can address them, and enable individuals at different levels in an academic organisation to demonstrate leadership for sustainability.

\subsection{Governance and leadership}

All universities have a responsibility to consider how they facilitate the graduation of responsible citizens with a sense of purpose who can think critically and compassionately, within current and future contexts, to influence change and make a difference in their community and beyond [18]. In order to meet the ambitious agenda set by the SDGs, UNESCO [81] advocates a whole-institution approach to ESD: 'the whole-institution approach should be strengthened with emphasis on the necessity for education institutions and communities to work together'. A whole institution approach is best supported by senior leadership and governance mechanisms to ensure that institutional ESD commitments are explicit and realised. The Guidance will support educators in the successful implementation of ESD by identifying who in institutions should lead and engage with the aims and intentions of the Guidance. It recognises the importance of strategic institution level commitment to progress ESD and includes strategic institution level drivers to steer leaders who are able to effect change at an institutional level. It may also be useful as an advocacy document for those wishing to support or progress an ESD agenda in their institution [28].

While it is recognised that a whole institution approach to ESD is beneficial, there are a number of models and principles defining sustainability leadership [36], and leadership for sustainability in universities can be achieved through a variety of roles and functions: 'Anyone seeking to influence another is a potential leader' [36]. Sustainability leaders recognise the need for a personal ethic and the challenge of dissonance that transformative learning can bring, but also recognise the positive benefits of innovation and plural perspectives [82]. Leadership can manifest in different forms and can also occur at different levels [36]. The Guidance is written to support embedding of ESD and sustainability leadership at different levels, whatever the level of senior commitment from the institution. The Guidance recognises that there are many ways in which ESD may be achieved and is not prescriptive about delivery.

Of course, universities differ widely in their forms, student cohorts, size, specialisms, national context and institutional cultures $[40,66]$ and thus will vary in how they perceive and provide governance supporting ESD. Many universities in developing countries have an emphasis on local community engagement and resolution of local issues; others may have more global relationships, with high numbers of international students. Universities have a significant role to play in communities and society. They employ large numbers of people and their staff often take up roles within society and businesses alongside their university work. Students are drawn from countries all over the world and therefore the learning journey of those students has potential to influence communities across the globe. Further, the way in which university-owned buildings and land are managed, and the values and behaviour of staff and students, will impact on the local physical environment and communities. The Guidance strives to recognise this diversity whilst offering legitimacy, examples, resources and pathways for different types of institution.

Some universities are pioneering, willing to take risks and explore radical paths, whilst others are more conservative, slower to shift their emphasis and concerned about public relations. In addition, some institutions are well advanced along the journey of sustainability whilst others are yet to properly begin. This plurality in interpretation and implementation of ESD will be a healthy outcome, providing the urgency for embedding ESD is recognised by all. Sustainability governance can be strengthened in different dimensions, including politics, profession, organization, knowledge, and the public [83], hence diverse leadership models are likely to emerge. The Guidance acknowledges different entry points for discussion as well as diverse potential roles from which leadership can champion ESD.

At a sectoral level, a clear mandate to include ESD in universities will encourage all institutions to consider or deepen ESD activity. Such leadership can emerge from relevant sectoral statutory organisations, external bodies or collective 
commitments. In the UK, some sustainability leadership has been lost or diminished in higher education (including the Higher Education Funding Council for England (HEFCE) and Higher Education Academy (HEA)) and the independent regulator for higher education in England, the Office for Students, has yet to establish strong sustainability credentials since its inception in 2018 [72]. External organisations such as the National Union of Students (NUS) and The Environmental Association for Universities and Colleges (EAUC) thus play a greater role in the support of sustainability progress. There are differences in the status of ESD across devolved nations within the UK [19, 84]. Given this complex sectoral arena in the UK, the Guidance discussed in this paper [28], developed through an expert advisory group, demonstrates sectoral leadership in ESD as it crosses public administration boundaries, while recognising that Guidance will need to be enacted in a context specific environment.

Statutory requirement for ESD has occurred for teacher training and continuing professional development (CPD) for school teaching in Scotland, but at higher education level there is reluctance to impose regulatory insistence and a greater reliance on higher education providers having the autonomy of choice in how they address ESD. Although the Guidance itself is not statutory, as of May 2021, there is a new requirement for higher education providers to consider ESD within all UK discipline benchmark statements, and the Guidance will offer a crucial resource and framing for the scope of ESD uptake across teaching and learning.

Networks and global institutions can also support sectoral leadership. UNESCO has a focus on ESD and supports universities worldwide [85]. The United Nations University Regional Centres of Expertise in ESD is a global network to support ESD across sectors. Within the UK, there are several instances, with particularly active examples being Regional Centre of Expertise (RCE) Learning for Sustainability Scotland, RCE Cymru (Wales), RCE Midlands (England) and RCE London (England). Sectoral initiatives such as the EAUC SDG Accord [64], the American Colleges and University President Climate Commitment [86] the Inter-University Sustainable Development Research Programme (IUSDRP) [73], or the European School of Sustainability Science and Research (ESSSR) [87], can also galvanise collective leadership that includes not only ESD but also emphasis on sustainability research and engagement with policy such as the SDGs.

The Guidance supports ESD leadership at different levels within universities. Leadership that can promote ESD in higher education institutions occurs at all scales in a nested and interlinked model, enabling a cascade of influence from any given point (Fig. 1). Different sources of leadership signals or intent emerge in educational provision in different ways and at different paces. University leadership is dispersed across roles [36]; however, there is increasing accountability for academics, so it is not always possible to engage in initiatives because they feel it is the right thing to do.

University principals and vice-chancellors have a significant leadership role to play in supporting ESD in their institutions [88]. Whilst they may have less of a specific role in designing curricula, they are critical in supporting a value-based culture and in creating trust and accountability in their universities. Senior support for structural and cultural enablers plus ground level sustainability enthusiasts are essential to create a virtuous cycle of community and sustainability action in universities [40]. Principals and vice-chancellors can also make clear leadership statements by signing up to accords and commitments as described above.

Senior leadership support can also emerge from a dean, pro-dean, faculty dean or other middle management position, depending on institution. At this level, leadership can support training in ESD for staff, offer rewards for ESD teaching and learning and link teaching and extra-curricular opportunities more effectively to give a whole institutional experience for students. However, practical change in sustainability in a university depends on more than senior governance support; it also demands action by academics [89].

The next level of leadership is thus that of the course or programme director. At this level, the academic has the ability to make significant curricular and pedagogic decisions that can cover sustainability topics and enable learning in such a way that students can gain sustainability competencies. Programme directors can usually gain institutional approval to alter forms of assessment and can strategically plan for coverage of ESD topics as relevant to the subject. Programme directors may also engage with professional accreditation expectations.

The individual academic can also have a leadership role, among their peers and within a class. They deliver curricula at module level and have the responsibility for co-designing innovative pedagogies and for student engagement. Academics can be change agents through their influence on graduates [52]. At this individual level, champions of ESD can emerge, and good practice examples can be recognised and rewarded, but many staff may feel frustrated by the barriers to ESD outlined above and require support from more senior leadership to enable them to effectively support ESD. The Guidance [28] can support them on their journey and can be used to justify and embolden their approach to learning.

Over the past decade, we have seen increasing leadership from students themselves in relation to ESD and other aspects of university sustainability. In the UK, the NUS has run a campaign to demonstrate student demand for ESD in universities and to support its provision. Young people have recently engaged extensively in different forms of 


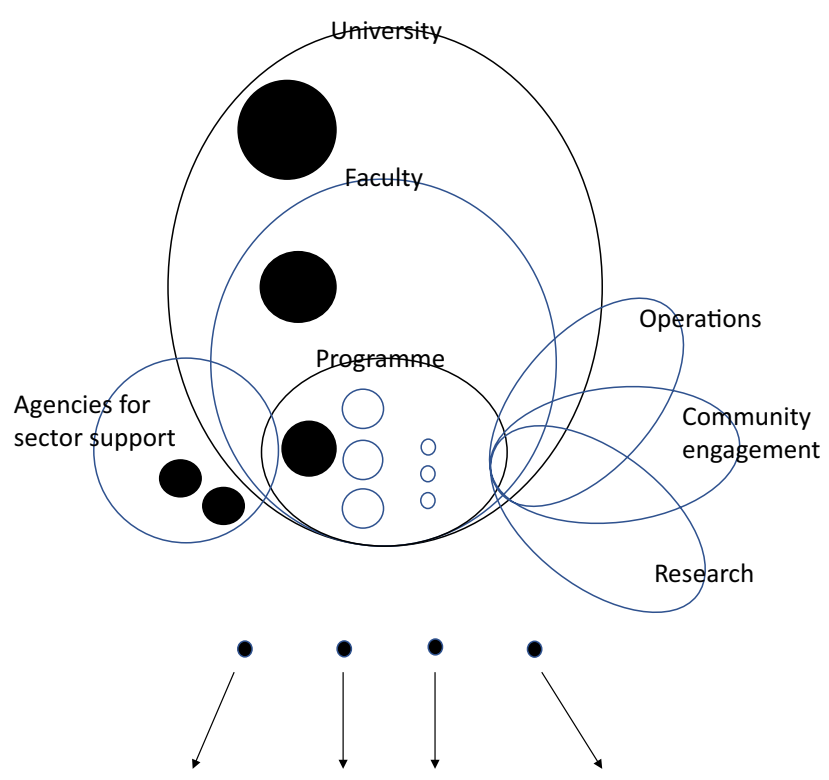

Fig. 1 The model of nested leadership in and through education for sustainable development in Universities. Within a programme, academic staff (clear circles) and programme leaders (filled circles) facilitate learning with students (small clear circles) who eventually graduate (small filled circles) with generic and specific sustainability competencies and fulfil leadership roles in communities and business. This process is facilitated by leadership at Faculty and University senior management (larger filled circles) and in Agencies for sector support. Those working in Operations, Community engagement and Research can also play a leading role in ESD through a whole institution approach. Since Operations, Community engagement and Research engage people outside of the institution (e.g. through procurement, student projects in the community, research on real world problems), teaching and learning can also practically link to stakeholders and issues beyond the university walls in a whole institution model

activism, especially in relation to the urgency for climate action, with imagination, commitment and determination. Student founded initiatives such as Rethinking Economics [90] are critical; this organisation has 52 groups in 23 countries and reflects the disillusionment of some economics students with traditional economics education in universities. It supports critical economics thinking [91] and promotes a critical ESD perspective.

Finally, we need to consider how universities can offer leadership within society through ESD and other aspects of a whole institution sustainability approach. For example, by producing graduates who will pursue sustainability in their work and personal lives; by demonstrating how professions can address sustainability issues; by engaging in partnership with local and global partners in sustainability initiatives; by providing mentorship and a leadership example in operational sustainability; and by increasing awareness of and information on sustainability locally and globally.

Aspects of leadership required to implement sustainability initiatives as relevant to ESD include:

- Recognition of the need for change and the dissonance and resistance that this may bring;

- A personal ethic and self-awareness in which to ground action;

- Ability to understand complex systems and to see the holistic nature of sustainability challenges;

- Collaborative leadership in which people are engaged and not coerced; and

- Understanding and integration of different perspectives [82].

Sustainability leadership requires nurturing of different competencies, drawn from those suggested by Wiek et al. [26] and including systems thinking, normative, anticipatory, strategic and inter-personal competencies [92]. The SDGs are not only technical responses, but require difficult decisions to be made and hence demand moral responsibility from leaders of states, institutions and organisations [9]. We thus need to ensure that those with any role in leadership for ESD in higher education, from individual staff to principals, students to those in sector governance, are supported to attain the general as well as specific competencies required to address sustainability challenges $[26,93]$. 


\subsection{Learning and teaching approaches}

ESD is an educational change agenda grounded in transformative learning and critical pedagogy. Factors identified as critical to the success of ESD in higher education include support for educators to develop ESD capabilities [21, 73]. ESD goes beyond the acquisition of information and focuses on supporting the development of the competencies, skills, attributes and values required to address sustainable development challenges [18]. The Guidance offers suggestions to inspire, inform and enable ESD to be designed into and adopted across curricula within the context of diverse disciplines. It acknowledges the importance of holistic, transformational, action-based education. The Guidance recognises that designing ESD into curricula can be achieved via whole curricular approaches, within core and optional modules, as multidisciplinary, interdisciplinary or transdisciplinary approaches in the formal curriculum or as co-curricular work-based learning or extracurricular activities such as working with community groups to embed problem solving for real-world situations. The approach adopted will depend on the context of the activity and the commitment from the institution [28].

The Guidance advocates that ESD requires constructively aligned teaching, learning and assessment activities designed to meet key sustainable development competencies and learning outcomes. Furthermore, it provides reflective questions to assess effectiveness of ESD by addressing key aspects such as stakeholder engagement, integrated curriculum design, student experience beyond the curriculum and institutional strategy [28].

\subsection{Discipline context}

Successful embedding of ESD requires providing staff with the resources and capabilities to engage with the concepts of ESD within the context of their own discipline [21]. The Guidance advocates that ESD can be considered as a lens through which all academic disciplines can be viewed and which enables us to examine current practices and alter them to pursue our visions of the future [94]. It supports learners across all academic disciplines in developing the general and specific subject relevant competencies $[26,43,93]$ and identifies useful approaches and resources for educators seeking to include ESD in a discipline context. UNESCO's key competencies for sustainability [43], emphasise the desired skills, attributes and values that can be developed through ESD. The competencies include critical thinking, systems thinking and anticipatory competency (futures thinking) and are appropriate for all disciplines, contexts and levels of learning. They enable students to become 'change agents', 'problem solvers' and 'transition managers' while promoting interdisciplinary and transdisciplinary ESD [26,93]. Our understanding of sustainability has changed in recent years, driven partly by the SDGs and their interactivity, emphasising the need for systems thinking and a holistic perspective $[3,17]$. The Guidance proposes that the SDGs thus offer a useful framework to scope the extent of sustainable development, and an excellent mechanism to engage with sustainability in practice. The 17 SDGs address global challenges, including those related to poverty, inequality, climate change, environmental degradation, peace and justice. The breadth of the SDGs means that they resonate with all academic disciplines and subject areas, while the interdisciplinary and interconnected focus of the 17 SDGs makes them an important and useful tool for the development of ESD approaches [25]. The Guidance also makes clear that the SDGs comprise a contemporary, heavily negotiated compromise, and that ESD enables universities to support students in developing the critical capacities to monitor and evaluate the efficacy and implications of this framework in a critically constructive manner. By providing a critical introduction to ESD, advice on ESD approaches and resources, the Guidance challenges universities to identify a new balance between disciplines and specific and generic competencies and discusses how to holistically position ESD across curricula [28].

QAA's Subject Benchmark Statements describe the nature of study and the academic standards expected of graduates in specific subject areas [95]. While accreditation procedures and disciplinary structures are perceived as barriers to embedding ESD content $[25,53]$, Subject Benchmark Statements and also professional accreditation procedures can, in fact, be complementary to the Guidance in the facilitation of ESD. For example, at the time of drafting this paper, prior to the requirement for consideration of ESD in benchmark statements, 85\% (51 of 60) of UK QAA Bachelor's degrees with honours subject benchmark statements [86], already referred to either the sustainability context $(50 \%)$ or the social, economic and/or environmental contexts of the discipline (35\%) and provided a valuable starting point for embedding ESD across a variety of academic disciplines (Fig. 2). Sustainable development is defined in many ways but includes economic, social and environmental aspects which are interconnected, overlapping 


\section{Benchmark Statements that include reference to sustainability, sustainable development or sustainability} context of the discipline

Accounting - Agriculture, Horticulture, Forestry, Food and Consumer Sciences - Archaeology - Architectural Technology - Art and Design - Biomedical Sciences - Biosciences - Business and Management - Chemistry -

Computing - Dance, Drama and Performance - Early Childhood Studies - Earth Sciences, Environmental

Sciences and Environmental Studies - Economics - Education Studies - Engineering - Events, Hospitality, Leisure, Sport and Tourism - Finance - Geography - Health Studies - Housing Studies - Landscape Architecture Land, Construction, Real Estate and Surveying - Materials - Physics, Astronomy and Astrophysics - Social Policy - Sociology - Theology and Religious Studies - Town and Country Planning - Veterinary Nursing

Benchmark Statements that include reference to social, economic and/or environmental contexts of the discipline

Anthropology - Architecture - Area Studies Communication, Media, Film and Cultural Studies Counselling and Psychotherapy - Creative Writing Criminology - Dentistry - Dietetics - English History - Languages, Cultures and Societies - Law Linguistics - Music - Paramedics - Politics and International Relations - Psychology - Social Work Welsh - Youth and Community Work

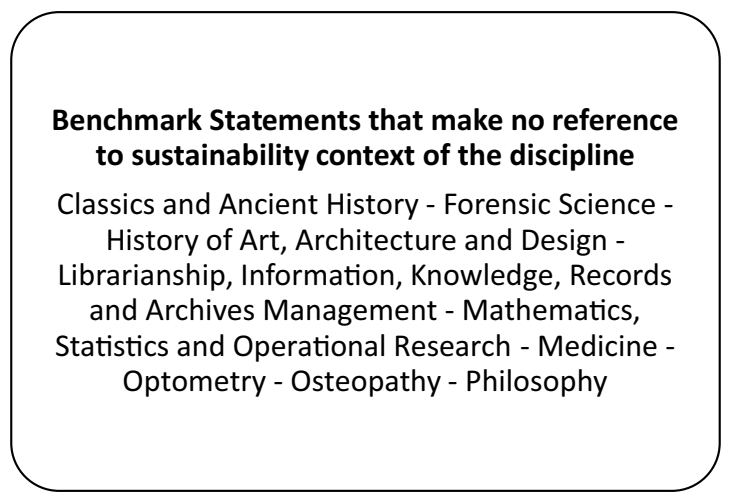

Fig. 2 UK QAA Bachelor's degrees with honours subject benchmark statements that refer to either the sustainability context of the discipline (50\%), the social, economic and/or environmental contexts of the discipline (35\%), or make no reference to the sustainability context of the discipline (15\%)

and interdependent [96]. The Guidance recognises that relationships with professional and regulatory bodies are important in encouraging learners and educators to collaborate widely to effect change [28]. Such bodies will be instrumental in strengthening advocacy for ESD across UK Higher Education. Through ESD, disciplinary excellence can come together with challenge-focused and competency-based education, with interdisciplinary approaches and with practitioners to more fully pursue sustainability [18].

\subsection{Measuring success}

Universities gain benefits from embedding ESD, including demonstrating the impact and relevance of the university and the wider sector to current and prospective students and staff and to other sectors [25]. The most significant benefit ESD will have is in developing the competencies of graduates to design and pursue sustainable futures [28], yet there is no globally agreed standard for how universities should measure and report on their progress in implementing ESD [25]. Instead, success in sustainability is recognised through a range of national and international sector awards, frameworks and league tables [25,36]. A number of these include measures of ESD. Of these, some are student led, others are sector or media led, all with differing reputations amongst institutions and sustainability leaders [36].

Examples of student-led approaches include the People and Planet University League and Responsible Futures. The People and Planet University League is a league table of UK universities ranked by environmental and ethical performance compiled by a student campaigning network, People and Planet. One of the twelve categories involves assessment of ESD [22]. Responsible Futures is an accreditation that seeks to ensure students have the knowledge and understanding, skills, and attributes needed to contribute positively to social responsibility and sustainability. The framework was launched in the UK in 2014 [97] and Students Organising for Sustainability International (SOS International) now supports whole-institution curriculum reform and accreditation worldwide [98]. Sector recognition mechanisms include Green Gown Awards and UNAI membership. EAUC Green Gown Award 'Next Generation Learning and Skills' category recognises achievement in the development of academic courses, skills and capabilities relevant to sustainability. Green Gown Awards have an increasing international presence [99]. The United Nations Academic Impact (UNAI) is a global initiative 
to align institutions of higher education with the United Nations. UNAI members are required to foster and promote ten UNAI Principles, one of which is 'A commitment to promoting sustainability through education' [85]. The media-led Times Higher Impact Rankings are the first global attempt to measure university progress specifically around the SDGs. Universities receive a score and a rank for their activities in each of the SDGs for which they submit data. Participation in the overall ranking requires universities to submit data to at least four SDGs one of which must be SDG 17: Partnerships for the Goals. One of the indicators for SDG 17 is that institutions 'Have a commitment to meaningful education around the SDGs across the university, in some programmes or in all programmes' and is equivalent to about seven percent of the overall score [24], though there is limited recognition that the SDGs should be considered as interconnected goals. These examples illustrate that each award, framework or league table has its own criteria for success. This lack of consistency can act as a barrier to ESD implementation at an institutional level. To counter this, the Guidance provides a clear set of principles and practices to accelerate implementation of ESD whatever success measures are recognised by institutions or the sector [28].

Principles of sustainability have been integrated into many university graduate attribute statements [58]. Through resources to support engagement with employers, the Guidance addresses issues such as how universities can prepare graduates to help employers meet sustainable development challenges [28]. However, while there is growing agreement on the competencies sustainability professionals should possess as well as the pedagogies to develop them, the practice of assessing graduates' sustainability competencies requires further development [79]. Graduate self-reporting via quantitative surveys appears to be the dominant approach to assess graduate capability in and professional application of sustainability related attributes [100]. Qualitative forms of assessment include reflective questions that can be addressed to either educator or student [93]. Given the need for broad sustainability education, it is recognised that efforts should be accelerated to develop more robust tools to assess graduate capability [79].

\section{Conclusions}

We have highlighted here the importance of embedding ESD in universities to enable them to fulfil their potential leadership role for individual and societal transformation towards sustainability. In this article, we suggest that sector-wide ESD Guidance is a valuable mechanism to support this. We adapted the Delphi methodology, aiming to obtain the most reliable consensus of opinion of an expert group, to publish such Guidance for the UK HE sector. Expertise is the desired goal for panel selection and is a feature which sets Delphi apart from other general forms of survey research [29]. However, remote, anonymous participation is also typically a requirement of the Delphi process. Anonymity in Delphi seeks to avoid influence of opinions of others, but may reinforce unaccountability [29]. We opted to use both remote and face-toface participation with identified particpants, supplemented by wider consultation with the sector to obtain consensus. A criticism of the approach used is that the Guidance may not fully reflect all viewpoints in order to achieve the best representation of consensus. However, we advocate the approach used, since those in HE who will ultimately act upon the results of the consultation were actively involved throughout the process [29]. Furthermore, the new requirement for all subject benchmarks to consider the Guidance can only strengthen its implementation.

While this work is UK based, it can act as a stimuls for embedding ESD in university curricula elsewhere. Through focusing on process, competencies and outcomes, the Guidance has been drafted in such a way that it can be applied across a range of government administrations, nationally and internationally.

There remains a challenge for institutions and for the sector to balance the extreme urgency of the nature, climate and inequalities crises that we face with a desire to retain existing models of higher education and not address fundamental questions regarding the role of universities. For universities to truly alter their paradigm and not merely shift their mode of provision, brave and visionary leadership is demanded. Universities need to transform internally to be able to adapt in the current knowledge economy, whilst retaining their historic collegial culture [101].

As this leadership challenge is taken up, however, we describe a nested leadership model in which sector wide agencies, university principals, senior managers, programme leaders, individual academic staff and students can all act as change agents by encouraging and implementing more and deeper forms of ESD. This is also a collaborative model in which cooperation at all levels is required to realise the potential of an institution and of the sector. Leadership within the institution thus nurtures the leadership potential of graduates, enabling universities to seed ideas and actions for the future that can be spread and flourish around the world, and flower within all other professional sectors. In an uncertain world, embedding ESD will thus enable universities to produce graduates with the capacities, competencies and mindsets 
to envision and pursue sustainable futures. This is probably one of the most important impacts of ESD. Embedding ESD will also consolidate the role of universities as innovative societal leaders and thinkers rather than reactive organisations.

We identified many of the barriers that universities face in embedding ESD and we analysed how the Guidance supports individuals, institutions and the sector in overcoming these, at least in part, to lead societal transformation through ESD. We support a diversity and plurality of approaches to ESD, and an encouragement of innovation and creativity within the sector. However, we conclude that challenges remain, including the need for academic staff to themselves be supported in gaining the competencies we wish to develop in our students. This focus on ESD may continue an erosion of research-teaching-community engagement boundaries and encourage a more integrated form of scholarship [52]. Education has long been seen as a power to change the world, and it may be that leadership for ESD at all levels within higher education can catalyse the transformation of universities, repurposing them for a more sustainable future.

Acknowledgements Members of the QAA-Advance HE advisory group updating the ESD Guidance for the UK HE sector. Thanks to Atholl Emmerson for the diagram.

Authors' contributions All authors whose names appear on the submission (1) made substantial contributions to the conception or design of the work; or the acquisition, analysis, or interpretation of data; or the creation of new software used in the work; (2) drafted the work or revised it critically for important intellectual content; (3) approved the version to be published; and (4) agree to be accountable for all aspects of the work in ensuring that questions related to the accuracy or integrity of any part of the work are appropriately investigated and resolved. All authors read and approved the final manuscript.

Funding Not applicable.

Data availability Not applicable.

Code availability Not applicable.

Declarations

Competing interests Not applicable.

Open Access This article is licensed under a Creative Commons Attribution 4.0 International License, which permits use, sharing, adaptation, distribution and reproduction in any medium or format, as long as you give appropriate credit to the original author(s) and the source, provide a link to the Creative Commons licence, and indicate if changes were made. The images or other third party material in this article are included in the article's Creative Commons licence, unless indicated otherwise in a credit line to the material. If material is not included in the article's Creative Commons licence and your intended use is not permitted by statutory regulation or exceeds the permitted use, you will need to obtain permission directly from the copyright holder. To view a copy of this licence, visit http://creativecommons.org/licenses/by/4.0/.

\section{References}

1. Rockström J, Steffen W, Noone K, Persson Å, Chapin FS III, Lambin E, Foley J. Planetary boundaries: exploring the safe operating space for humanity. Ecol Soc. 2009;14(2):33.

2. Raworth K. A safe and just space for humanity: can we live within the doughnut? Washington, DC: Oxfam; 2012.

3. UN (2015). Transforming our world: the 2030 Agenda for Sustainable Development A/RES/70/1. https://sustainabledevelopment.un. org/content/documents/21252030\%20Agenda\%20for\%20Sustainable\%20Development\%20web.pdf

4. IPCC. Climate change 2014: synthesis report. Geneva: IPCC; 2014.

5. CIEEM. Climate emergency and biodiversity crisis: the facts and figures. Chartered Institute of Ecology and Environmental Management briefing paper, September 2019; 2019. https://cieem.net/wp-content/uploads/2019/09/Climate-Emergency-and-Biodiversity-Crisis-TheFacts-and-Figures.pdf

6. East M, White RM. Reflecting on the emergence of the UN sustainable development goals: a call for action in Scotland. Report for Scottish Government and COSLA; 2016, p. 55

7. Mironenko O, Lucas PL, Tarasova N, Zlinszky J. Sustainable development goals: why do we need them? Soc Evol History. 2015;14(2):176-90.

8. Freistein K, Mahlert B. The potential for tackling inequality in the sustainable development goals. Third World Quarterly. 2016;37(12):2139-55.

9. Nawn N. For sustainable SDGs: righting through responsibilities. J Hum Devel Capabil. 2015;16(4):625-30.

10. Makwana R. The truth about poverty and how to address it. Policy and practice a development education review. Centre Glob Educ. 2016;22(22):141-51.

11. Hope J. The anti-politics of sustainable development: environmental critique from assemblage thinking in Bolivia. Trans Instit Brit Geograph. 2020. https://doi.org/10.1111/tran.12409.

12. Johnston LF, editor. Higher education for sustainability: cases, challenges, and opportunities from across the curriculum. New York: Routledge; 2013. 
13. Sterling S. The sustainable university: challenge and response. In: Sterling S, Maxey L, Luna H, editors. The Sustainable University. Progress and Prospects. London: Routledge; 2013. p. 17-50.

14. UNESCO. What is education for sustainable development?. 2019. https://en.unesco.org/themes/education-sustainable-development/ what-is-esd. Accessed 2 Jan 2021.

15. United Nations Environment Programme (UNEP). Global environmental outlook 6: healthy planet healthy people. Cambridge: Cambridge University Press; 2019. p. 4.

16. UN. Decade of Action; 2020. https://www.un.org/sustainabledevelopment/decade-of-action/. Accessed 19 Oct 2020.

17. UN. The sustainable development goals report 2019. 2019. https://unstats.un.org/sdgs/report/2019/The-Sustainable-DevelopmentGoals-Report-2019.pdf. Accessed 19 Oct 2020.

18. Price E, Longhurst J, White R, Preist C, Mori K, Robinson Z, Baughan P, Gough G, Hayles C, Higgins P, Molthan-Hill P, Hack C, Kemp S. Education for sustainable development in higher education. Environ Sci. 2020;29(4):38-45.

19. Martin S, Dillon J, Higgins P, Peters C, Scott W. Divergent evolution in education for sustainable development policy in the United King dom: current status, best practice, and opportunities for the future. Sustainability. 2013;5(4):1522-44.

20. QAA/HEA. Education for sustainable development: guidance for UK higher education providers; 2014. https://www.qaa.ac.uk/docs/qaa/ quality-code/education-sustainable-development-guidance-june-14.pdf?sfvrsn=1c46f981_8. Accessed 2 Jan 2021.

21. Fiselier ES, Longhurst JWS, Gough GK. Exploring the current position of ESD in UK higher education institutions. Int J Sustain High Educ. 2018;19(2):393-412. https://doi.org/10.1108/IJSHE-06-2017-0084.

22. People and Planet. People and planet university league. methodology and assessment. Education for Sustainable Development. 2020. https://peopleandplanet.org/university-league/methodology/9-education-sustainable. Accessed 7 Dec 2020.

23. Association for the Advancement of Sustainability in Higher Education (AASHE). The sustainability tracking, assessment and rating system (STARS). 2021. https://stars.aashe.org/. Accessed 25 Jan 2021.

24. THE. The impact rankings methodology 2021.Version 1.0; 2020 https://the-impact-report.s3-eu-west-1.amazonaws.com/Impact_Guide_ 2021/THE+ImpactRankings+METHODOLOGY+2021_A4_Final_based+on+v1.3.2.pdf. Accessed 7 Oct 2020.

25. SDSN. Accelerating education for the SDGs in universities: a guide for universities, colleges, and tertiary and higher education institutions. Sustainable Development Solutions Network (SDSN), New York; 2020.

26. Wiek $A$, Withycombe $L$, Redman CL. Key competencies in sustainability: a reference framework for academic program development. Sustain Sci. 2011;6:203-18. https://doi.org/10.1007/s11625-011-0132-6.

27. Brundiers K, Barth M, Cebrián G, Cohen M, Diaz L, Doucette-Remington S, Dripps W, Habron G, Harré N, Jarchow M, Losch M, Michel J, Mochizuki Y, Rieckmann M, Parnell R, Walker P, Zint M. Key competencies in sustainability in higher education-toward an agreed-upon reference framework. Sustain Sci. 2021;16:13-29. https://doi.org/10.1007/s11625-020-00838-2.

28. QAA/Advance HE. Education for sustainable development guidance. 2020. https://www.qaa.ac.uk/quality-code/education-for-susta inable-development and https://www.advance-he.ac.uk/knowledge-hub/education-sustainable-development-guidance. Accessed 29 Mar 2021.

29. Clayton MJ. Delphi: a technique to harness expert opinion for critical decision-making tasks in education. Educ Psychol. 1997;17(4):37386. https://doi.org/10.1080/0144341970170401.

30. Wright TSA. Developing research priorities with a cohort of higher education for sustainability experts. Int J Sustain High Educ. 2007;8:3443. https://doi.org/10.1108/14676370710717571.

31. Finlay L, Gough B, editors. Reflexivity: a practical guide for researchers in health and social sciences. Hoboken: Wiley; 2008.

32. Zilahy G, Huisingh D. The roles of academia in Regional Sustainability Initiatives. J Clean Prod. 2009;17:1057-66.

33. Sterling S, Maxey L, Luna H. The Sustainable University. Porgress and Prospects. London: Routledge; 2013. p. 23.

34. Stough T, Ceulemans K, Lambrechts W, Cappuyns V. Assessing sustainability in higher education curricula: a critical reflection on validity issues. J Clean Prod. 2018;172:4456-66.

35. Haddock-Fraser J, Rands P, Scoffham S. Leadership for sustainability in higher education. London: Bloomsbury Academic; 2018.

36. Haddock-Fraser J, Gorman D. Building your influence: the role of the smart sustainability Leader. Emerald Open Res. $2020 ; 2: 53$.

37. Pee S, Vululleh N. Role of universities in transforming society: challenges and practices. In: Sengupta E, Blesinger $P, M a h o n e y ~ C$, editors. International perspectives on policies, practices and pedagogies for promoting social responsibility in higher education (innovations in higher education teaching and learning), vol. 32. Bingley: Emerald Publishing Limited; 2020. p. 67-79.

38. British Council. The educational pathways of leaders. An international comparison. British Council. 2015. https://www.britishcouncil. org/sites/default/files/edupathwaysofleadersreport_final.pdf. Accessed 7 Dec 2020.

39. White RM. Sustainability research: a novel mode of knowledge generation to explore alternative ways for people and planet. In: Sterling $\mathrm{S}$, Maxey L, Luna H, editors. The sustainable university: progress and prospects. Abingdon: Routledge; 2013.

40. White RM, Harder M. The journey towards sustainability via community: lessons from two UK universities. In: Sterling S, Maxey L, Luna $\mathrm{H}$, editors. The sustainable university: progress and prospects. Abingdon: Routledge; 2013.

41. Orr DW. Earth in mind: on education, environment, and the human prospect. Washington DC: Island Press; 2004.

42. Grant J. The new power university. London: Pearson Education; 2021.

43. UNESCO. Education for sustainable development learning objectives. Paris: UNESCO; 2017.

44. Cortese AD. The critical role of Higher Education in creating a sustainable future. Plan High Educ. 2003;31:15-22.

45. Sterling S. The future fit framework. An introductory guide to teaching and learning for sustainability in HE. York: Higer Edcuation Academy; 2012.

46. Thomas I. Critical thinking, transformative learning, sustainable education, and problem-based learning in universities. J Transform Educ. 2009;7(3):245-64.

47. Barlett $\mathrm{P}$, Chase $\mathrm{G}$. Sustainability in higher education; stories and strategies for transformation (Urban and Industrial Environments). Massachusetts: MIT Press; 2013.

48. Drayson R, Bone E, Agombar J, Kemp S. Student attitudes towards and skills for sustainable development. York: The Higher Education Academy; 2014. 
49. Johnston L, editor. Higher education for sustainability: cases, challenges and opportunities from across the curriculum. Oxford: Routledge; 2013.

50. Seatter CS, Ceulemans K. Teaching sustainability in higher education: pedagogical styles that make a difference. Can J High Educ. 2017;47:47-70.

51. Wakefield JS, Grice CE. The teaching sustainability mini-pilot: a faculty learning community building curriculum for students' sustainability thinking. In: Sengupta E, Blessinger P, Yamin TS, editors. Teaching and learning strategies for sustainable development (innovations in higher education teaching and learning), vol. 19. Bingley: Emerald Publishing Limited; 2020. p. 143-58. https://doi.org/10.1108/S2055364120200000019013.

52. White RM, et al. Who Am I? The role(s) of an academic at a 'Sustainable University.' In: Leal Filho W, et al., editors. Integrative approaches to sustainable development at university level. World Sustainability Series. Berlin: Springer; 2014.

53. Leal Filho W, Emblen-Perry K, Molthan-Hill P, Mifsud M, Verhoef L, Azeiteiro U, Bacelar-Nicolau P, de Sousa L, Castro P, Beynaghi A, Boddy J, Lange Salvia A, Frankenberger F, Price E. Implementing innovation and sustainability at universities around the world. Sustainability. 2019;11:3807.

54. NUS. NUS sustainability skills survey 2018-19; 2019 https://sustainability.nus.org.uk/resources/nus-sustainability-skills-survey-20182019. Accessed 7 Dec 2020.

55. Financial Times. Jobseekers want employers to commit to meaningful social impact; 2019 . https://www.ft.com/content/39d1367ce445-11e9-b112-9624ec9edc59. Accessed 7 Dec 2020.

56. Sterling S. Sustainable education: revisioning learning and change. Dartington: Green Books; 2001.

57. Drayson R. Employer attitudes towards, and skills for, sustainable development. Executive summary: employers. York: The Higher Education Academy; 2015.

58. Holdsworth S, Thomas I, Sandri O. Assessing graduate sustainability attributes using a vignette/scenario approach. J Educ Sustain Dev. 2018;12:120-39.

59. The Guardian. 'People want a job with purpose': why businesses are becoming more sustainable; 2020. https://www.theguardian. com/guardian-green-jobs/2020/oct/19/people-want-a-job-with-purpose-why-businesses-are-becoming-more-sustainable

60. Schaltegger S, Beckman M, Hockerts K. Collaborative entrepreneurship for sustainability. Creating solutions in light of the UN sustainable development goals. Int J Entrepreneurial Vent. 2018. https://doi.org/10.1504/IJEV.2018.092709.

61. Page Group. Top Skill of 2020: Intrapreneurship—what is it and why is it important?. 2020. https://www.michaelpage.co.uk/100-indemand-skills-2020. Accessed 7 Dec 2020.

62. Shrivastava P, Kennelly JJ. Sustainability and place-based enterprise. Organ Environ. 2013;26:83-101.

63. Bank of England. Breaking the Tragedy of the Horizon-climate change and financial stability. Speech given by Mark Carney Governor of the Bank of England, Chairman of the Financial Stability Board to Lloyd's of London, 29 September 2015; 2015. https://www. bankofengland.co.uk/-/media/boe/files/speech/2015/breaking-the-tragedy-of-the-horizon-climate-change-and-financial-stability. pdf?la=en\&hash=7C67E785651862457D99511147C7424FF5EA0C1A. Accessed 30 Dec 2020.

64. Goldman Sachs. Sustainable finance: the imperative and the opportunity. Goldman Sachs 2019 Sustainability Report; 2020. https:// www.goldmansachs.com/s/sustainability-report/index.html. Accessed 30 Dec 2020.

65. Avila LV, Leal Filho W, Brandli L, MacGregor C, Molthan-Hill P, Ozuyar PG, Moreira R, M.,. Barriers to innovation and sustainability at Universities around the world. J Clean Prod. 2017;164:1268-78.

66. Denman BD. What is a university in the 21st century? High Educ Manage Policy. 2009;17(2):9-28.

67. Doring A. Challenges to the academic role of change agent. J Furth High Educ. 2002;26:139-48.

68. Martin R. Academic activism. PMLA. 2009;124:838-46.

69. Apple M. Democratic education in neoliberal and neoconservative times. Int Stud Sociol Educ. 2011. https://doi.org/10.1080/09620 214.2011.543850.

70. Blewitt J. EfS: contesting the market model of higher education. In: Sterling S, Maxey L, Luna H, editors. The sustainable university: progress and prospects. Abingdon: Routledge; 2013.

71. Young OR, Berkhout F, Gallopin GC, Janssen MA, Ostrom E, Van Der Leeuw S. The globalization of socio-ecological systems: an agenda for scientific research". Glob Environ Chang. 2006;16:304-16.

72. White. Towards critical engagement of tertiary education with the UN sustainable development goals: reflections on UK stakeholder debates. In: International commission on education for sustainable development practice report, 2nd Edition, May 2019.

73. Leal Filho W, Shiel C, Paço A, Mifsud M, Avila LV, Brandli LL, Molthan-Hill P, Pace P, Azeiteiro UM, Vargas VR, Caeiro S. Sustainable development goals and sustainability teaching at universities: falling behind or getting ahead of the pack? J Clean Prod. 2019;232:285-94.

74. Sterling S. Higher education, sustainability, and the role of systemic learning. In: Corcoran PB, Wals AEJ, editors. Higher education and the challenge of sustainability. Dordrecht: Springer; 2004. https://doi.org/10.1007/0-306-48515-X_5.

75. Sheil C. Leadership. In: Sterling S, Maxey L, Luna H, editors. The sustainable university. Progress and prospects. London: Routledge; 2013. p. 110-31.

76. Sipos Y, Battisti B, Grimm K. Achieving transformative sustainability learning: engaging head, hands and heart. Int J Sustain High Educ. 2008;9:68-86. https://doi.org/10.1108/14676370810842193.

77. Koger S, Scott B. Psychology and environmental sustainability: a call for integration. Teach Psychol. 2007;34(1):10-8.

78. Koger S, Scott B. Teaching psychology for sustainability: the why and how. Psychol Learn Teach. 2016;15(3):214-25.

79. Redman A, Wiek A, Barth M. Current practice of assessing students' sustainability competencies: a review of tools. Sustainabil Sci. 2020. https://doi.org/10.1007/s11625-020-00855-1.

80. QAA. The UK quality code for higher education; 2018. https://www.qaa.ac.uk/quality-code. Accessed 2 Jan 2021.

81. UNESCO. Framework for the implementation of education for sustainable development (ESD) beyond 2019. 2019b. https://unesd oc.unesco.org/ark:/48223/pf0000370215.locale=en. Accessed 2 Jan 2021.

82. Ferdig MA. Sustainability leadership: co-creating a sustainable future. J Chang Manag. 2007;7(1):25-35. https://doi.org/10.1080/ 14697010701233809. 
83. Niedlich S, Kummer B, Bauer M, Rieckmann M, Bormann I. Cultures of sustainability governance in higher education institutions: a multi-case study of dimensions and implications. High Educ Q. 2020;74(4):373-90.

84. Hayles CS. Embedding education for sustainable development through the well-being of future generations (Wales) Act 2015. Eur J Sustain Dev. 2018;7(4):22-32. https://doi.org/10.14207/ejsd.2018.v7n4p22.

85. UN. United Nations Academic Impact Principles. 2020. https://academicimpact.un.org/content/principles. Accessed 7 Dec 2020.

86. Dyer G, Dyer M. Strategic leadership for sustainability by higher education: the American College \& University Presidents' Climate Commitment. J Clean Prod. 2017;140:111-6.

87. Leal Filho W, Price E, Wall T, Shiel C, Azeiteiro UM, Mifsud M, Brandli L, Farinha CS, Caeiro S, Lange Salvia A, Ruy Vasconcelos C, Olim de Sousa L, Pace P, Doni FV, Avila L, Fritzen B, Le Vasseur TJ. COVID-19: the impact of a global crisis on sustainable development teaching. Environ Dev Sustain. 2021. https://doi.org/10.1007/s10668-020-01107-z.

88. Association of University Leaders For a Sustainable Future (AULSF). Talloires Declaration; 1990. http://ulsf.org/talloires-declaration/. Accessed 30 Jan 2021.

89. Leal Filho W, Skanavis C, Kounani A, Brandli LL, Chris Shiel C, do Paço A, Pace P, Mifsud M, Beynaghi A, Price E, Lange Salvia A, Wil M, Shulla K. The role of planning in implementing sustainable development in a higher education context. J Clean Prod. 2019;235:678-87.

90. Rethinking Economics; 2021. http://www.rethinkeconomics.org. Accessed 12 Jan 2021.

91. Earle J, Moran C, Ward-Perkins Z. The econocracy: the perils of leaving economics to the experts. Manchester University Press; 2016.

92. Savage E, Tapics T, Evarts J, Wilson J, Tirone S. Experiential learning for sustainability leadership in higher education. Int J Sustainabil High Educ. 2015. https://doi.org/10.1108/IJSHE-10-2013-0132.

93. Giangrande N, White RM, East M, Jackson R, Clarke T, Salo Coste M, Penha-Lopes G. A competency framework to assess and activate education for sustainable development: addressing the UN sustainable development goals 4.7 challenge. Sustainability. 2019;11:2832. https://doi.org/10.3390/su11102832.

94. UNESCO. Education for sustainable development lens: a policy and practice review tool. 2010. https://unesdoc.unesco.org/ark:/48223/ pf0000190898. Accessed 1 Jan 2021.

95. QAA. Subject Benchmark Statements. 2020. https://www.qaa.ac.uk/quality-code/subject-benchmark-statements. Accessed 30 Dec 2020.

96. Redclift M. Sustainable development (1987-2005): an oxymoron comes of age. Sustain Dev. 2005;13(4):212-27.

97. SOS UK (Students Organising for Sustainability UK). Responsible futures overview. 2020. https://sustainability.nus.org.uk/responsiblefutures/about. Accessed 4 Jan 2021.

98. SOS International (Students Organising for Sustainability International) (udated). https://sos.earth/. Accessed 4 Jan 2021.

99. EAUC. Green gown awards categories and criteria 2020. 2020. https://www.greengownawards.org/categories-criteria-2020\#Next\% 20Generation\%20Learning\%20and\%20Skills. Accessed 4 Jan 2020.

100. Sandri O, Holdsworth S, Thomas I. Vignette question design for the assessment of graduate sustainability learning outcomes. Environ Educ Res. 2018;24:406-26.

101. Harloe M, Perry B. Repenser l'université sans la vider de son sens: engagements externes et transformations internes de l'université dans l'économie du savoir. Politiques et gestion de l'enseignement supérieur. 2005;2:31-45.

Publisher's Note Springer Nature remains neutral with regard to jurisdictional claims in published maps and institutional affiliations. 